\title{
Caregiver satisfaction with a multidisciplinary community-based rehabilitation programme for children with cerebral palsy in South Africa
}

\author{
Magugu Ngubane ${ }^{a}$ iD and Verusia Chetty ${ }^{\text {* }}$ (D) \\ ${ }^{a}$ Discipline of Physiotherapy, School of Health Sciences, University of KwaZulu-Natal, Durban, South Africa \\ *Corresponding author, email: chettyve@ukzn.ac.za
}

This study sought to determine the levels of satisfaction and experiences of caregivers with a multidisciplinary rehabilitation programme. A total of 26 caregivers were recruited at 3 health settings in South Africa. A survey based on the Multidimensional Assessment of Parental Satisfaction for Children with Special Needs and focus-group discussions were conducted at the end of programme. The majority of the respondents were mothers and unemployed. The participants were generally satisfied with the rehabilitation. However, participants held on to myths, stereotypes, and beliefs about the cause of disability and explained the impact of stigma on having a disabled child in their communities. Caregivers perceived the benefit of rehabilitation but believed that lack of communication and consultation with health professionals limited the care.

Keywords: caregivers, cerebral palsy, multidisciplinary team, rehabilitationsatisfaction

\section{Introduction}

Cerebral palsy (CP) is the commonest cause of disability in children with a global prevalence of 1.5 to more than 4 children per 1000 children living with this condition. ${ }^{1} \mathrm{CP}$ is classified as a group of disorders with motor impairments as the hallmark feature ranging from minor to major dysfunction. Commonly associated with comorbid cognitive and sensory disorders resulting from disturbance in the development of an infant or foetal brain, which remain permanent in nature, ${ }^{2,3}$ these impairments result in activity limitations and inhibited participation in daily activities as well as social recreational interaction. 4,5 Children with $\mathrm{CP}$ require a comprehensive multidisciplinary rehabilitation approach to maintain and improve function and prevent secondary complications. ${ }^{4,6}$ The multidisciplinary team (MDT) managing children with $\mathrm{CP}$ comprises various health professionals, including doctors (neurologists and paediatricians), nurses, physiotherapists, occupational therapists, speech and language therapists, psychologists, and social workers. ${ }^{7}$ Each professional has a varied role in the team but need to collaborate in order to achieve optimal care. Roles and expectations of professionals span early detection, acute care, physical and cognitive rehabilitation intervention, timely referral and psychosocial support with the aim of integrating children back into their communities. ${ }^{8}$

The MDT in a South African public domain manages children with CP from primary care settings through to tertiary settings. There is, however, a shift from centrally situated institutions of health care toward the primary health care model (clinics within the community) as it is fundamental for South African healthcare to become accessible to the larger population. Zimbabwe shares a similar governing infrastructure within its health care systems. A study by Dambi and Jelsma in $2014^{3}$ compared a communitybased model and hospital-based intervention for children with $\mathrm{CP}$ in Zimbabwe, which shows evidence of preferred outcomes within the community-based intervention. While the shift is still in its development and implementation stages, principles of practice for the MDT requires that the issues of access in such resource-limited settings be addressed., 79 One of the strategies that has been identified in rehabilitation research within countries with such political climates is task shifting. Task shifting is the training of laypersons, family and community members in skills of rehabilitative care in order to address the need within the communities and the lack of care due to shortage of staff and financial constraints among other barriers to rehabilitation. ${ }^{10}$

Compliance with rehabilitation is directly related to levels of satisfaction and influences commitment to the intervention. ${ }^{3}$ In the rehabilitative care of children with $\mathrm{CP}$, the involvement of the caregivers and their level of satisfaction is of importance as their participation has an impact on the rehabilitation goals. ${ }^{3}$ Furthermore, satisfaction with rehabilitation intervention is an imperative outcome that is believed to influence the emotional well-being of carers and impacts on a child's psychology. ${ }^{11}$ Scarcity in caregiver satisfaction and perception of rehabilitation is evident in resource-poor settings such as South Africa, thus this study is crucial in informing research for rehabilitation professionals involved in the management of children with CP.

This study's emphasis was focused on caregivers of children with $\mathrm{CP}$ who were involved in rehabilitation within a task-shifting approach. The study offered a rehabilitation intervention programme addressing the needs of children with $\mathrm{CP}$ by capacitating the caregivers; thereafter the caregivers' level of satisfaction with the intervention programme and perceptions relating to rehabilitation practice were investigated.

\section{Methodology}

This study is phased within a larger project in three purposively selected healthcare settings within semi-rural communities in the province of KwaZulu-Natal, South Africa. A mixed-methods approach using both qualitative and quantitative paradigms was used to investigate and explore a multidisciplinary six-week rehabilitation intervention programme for children with $\mathrm{CP}$ and their caregivers. The sessions were conducted on a weekly basis at each of the sites in a large seminar room/gym. A team of rehabilitation professionals planned the structured six-week programme. An occupational therapist, a speech and language therapist and a physiotherapist formed the core team. The physiotherapist, who was skilled in neurodevelopmental training 
Table 1: Six-week intervention sessions

\begin{tabular}{|c|c|c|c|}
\hline Week & Educational theme & Activity & Rehabilitation outcomes \\
\hline 1 & What is cerebral palsy? & Presentation & Identifying CP and needs for rehabilitation \\
\hline 2 & $\begin{array}{l}\text { Challenges when caring for a child with cerebral } \\
\text { palsy }\end{array}$ & Presentation & $\begin{array}{l}\text { Understanding the psychosocial demands of } \\
\text { caregivers and role of the MDT }\end{array}$ \\
\hline 3 & Importance of rehabilitation & Group therapy with children & $\begin{array}{l}\text { Demonstrated mat-work, positioning and } \\
\text { joint-protection techniques }\end{array}$ \\
\hline 4 & Importance of stimulation & $\begin{array}{l}\text { Toy-making with group and identification of } \\
\text { appropriate play equipment }\end{array}$ & $\begin{array}{l}\text { Demonstrated play therapy techniques and } \\
\text { selection of appropriate toys by caregivers }\end{array}$ \\
\hline 5 & Importance of positioning and feeding & $\begin{array}{l}\text { Demonstrated correct positioning and feeding } \\
\text { with each caregiver }\end{array}$ & $\begin{array}{l}\text { Appropriate selection of food Preparation for } \\
\text { feeding Correct position for feeding }\end{array}$ \\
\hline 6 & Education on empowerment of communities & Community awareness and stigma presentation & $\begin{array}{l}\text { Community-based rehabilitation project ideas } \\
\text { Educating the community }\end{array}$ \\
\hline
\end{tabular}

as a postgraduate specialty, was responsible for executing the intervention. Table 1 summarises the intervention programme for the six weeks. The educational session always initiated the day's events and on some days the caregivers had individual contact with the therapist. The educational sessions were based on evidence that emerged from managing children living with CP. Therapists delved into basic understanding of the condition and the importance of rehabilitation, as well as addressing challenges when caring for children with CP. The group therapy included mat-work, practical sessions on positioning and joint protection, and play therapy as well as toy-making.

This study addressed the level of satisfaction following the sixweek programme and experiences of the caregivers regarding rehabilitation at the various sites.

\section{Design}

For this phase of the study the authors used a cross-sectional survey with closed-ended questions as well as feedback focusgroup discussions with all the caregivers following the six-week intervention. This triangulation of positivist and naturalistic paradigms allows for strengthening of findings in a field with a paucity of research. ${ }^{12}$

\section{Participant recruitment}

Once approval was obtained from the University of KwaZuluNatal, permission was obtained from the relevant health and institutional authorities governing the three public healthcare sites in KwaZulu-Natal. Thereafter children with caregivers were recruited during their scheduled sessions at the respective sites. All caregivers consented voluntarily to participate in the study and no incentives were offered at any point in the study.

\section{Data collection}

A survey was conducted with caregivers at the completion of the six-week programme and a focus-group discussion was held with the three groups at each site. There were 10 caregivers in attendance at one of the health care sites and 8 at each of the other two sites.

\section{Data-collection instrumentation}

Researchers derived a survey for the local context using the Multidimensional Assessment of Parental Satisfaction (MAPS) for Children with Special Needs. ${ }^{13}$ The dimensions of care, i.e. developmentally appropriate care; family-centred care; coordinated care; technical competence; and interpersonal competence were used as the framework for questions. The questions are included in Table 2 under the results of the study. The instrument was translated into isiZulu and the researcher conducted the focus group and intervention programme in an isiZulu medium. The survey comprised a section for demographic data and 12 questions on levels of satisfaction posed to the caregivers. The scale included poor, neutral and excellent. All the questions were positively framed. The pilot study was conducted on rehabilitation staff and six caregivers from one of the study sites who were not included in the sample of the larger intervention programme. The same rehabilitation staff and two researchers appraised the tool for content validity.

The focus-group discussions were conducted in the same space as the sessions after the six-week intervention programme. A focus-group guide was used to inform discussions and included experiences of rehabilitation services and the six-week programme, as well recommendations for implementation of such programmes. Data were recorded using a Dictaphone, OLYMPUS VN-425PC Digital Voice Recorder and transcribed verbatim following the focus-group discussions.

\section{Data analysis}

The quantitative data from the survey were analysed using the Statistical Package for Social Sciences (SPSS ${ }^{\circledR}$ ) version 21.0 (IBM Corp, Armonk, NY, USA) and was interpreted and reflected using descriptive statistics. Nvivo $10^{\circledR}$ (QSR International (UK) Ltd Daresbury, UK) was used for thematic analysis of the narratives arising from the discussions following the six-week programme.

\section{Results}

Three sites within semi-rural communities in the province of KwaZulu-Natal, South Africa were purposively selected as they offered rehabilitation to children with CP. Twenty-six caregivers, who were all female and of African ethnicity, consented to participate in the study. They were conveniently recruited at the respective sites when they attended their healthcare visit. The preferred language medium was isiZulu.

Most of the caregivers accompanying the children were mothers $(88 \%, n=23)$ while $11 \%(n=3)$ were grandmothers. The majority were unemployed $(85 \%, n=22)$ and 22 of the caregivers were unmarried woman.

The MAPS questionnaire framed the themes of the level of satisfaction enquiry. ${ }^{13}$ Table 2 depicts the scores from the participants for each question. The responses are reflected in percentages.

The focus-group discussions were analysed using Nvivo $10^{\circledR}$ and the themes that emerged were read and re-read until the researchers agreed on the thematic representation of the data. 
Table 2: Caregivers' level of satisfaction with the six-week rehabilitation intervention

\begin{tabular}{|c|c|c|c|}
\hline Question & Poor & Neutral & Rating excellent \\
\hline $\begin{array}{l}\text { How would you rate your level } \\
\text { of satisfaction with the quality of } \\
\text { the six-week intervention }\end{array}$ & $0 \%$ & $15 \%$ & $85 \%$ \\
\hline $\begin{array}{l}\text { How well did the staff deal with } \\
\text { your needs }\end{array}$ & $0 \%$ & $23 \%$ & $77 \%$ \\
\hline $\begin{array}{l}\text { What did you think of the quali- } \\
\text { ty of care you received }\end{array}$ & $0 \%$ & $15 \%$ & $85 \%$ \\
\hline $\begin{array}{l}\text { How did you find the explana- } \\
\text { tion of procedure/treatment } \\
\text { provided }\end{array}$ & $0 \%$ & $8 \%$ & $92 \%$ \\
\hline $\begin{array}{l}\text { How did you find the explana- } \\
\text { tion of medical condition and } \\
\text { treatment }\end{array}$ & $0 \%$ & $15 \%$ & $85 \%$ \\
\hline $\begin{array}{l}\text { How would you rate your level } \\
\text { of satisfaction with the referral } \\
\text { to other healthcare profes- } \\
\text { sionals }\end{array}$ & $0 \%$ & $10 \%$ & $90 \%$ \\
\hline $\begin{array}{l}\text { How would you rate your level } \\
\text { of satisfaction with the explana- } \\
\text { tion of discharge and follow-up } \\
\text { care instructions }\end{array}$ & $0 \%$ & $46 \%$ & $54 \%$ \\
\hline $\begin{array}{l}\text { How did you find the courtesy } \\
\text { and concern you received from } \\
\text { the rehabilitation healthcare } \\
\text { worker who treated your child }\end{array}$ & $0 \%$ & $38 \%$ & $62 \%$ \\
\hline $\begin{array}{l}\text { How did you feel about the re- } \\
\text { habilitation healthcare worker's } \\
\text { concern about your confidenti- } \\
\text { ality and privacy }\end{array}$ & $0 \%$ & $62 \%$ & $38 \%$ \\
\hline $\begin{array}{l}\text { How did you feel about your in- } \\
\text { volvement in treatment sessions }\end{array}$ & $0 \%$ & $23 \%$ & $77 \%$ \\
\hline $\begin{array}{l}\text { What do you think about the } \\
\text { material given about the servic- } \\
\text { es, content and understanding }\end{array}$ & $0 \%$ & $27 \%$ & $73 \%$ \\
\hline $\begin{array}{l}\text { How would you rate the } \\
\text { exercises }\end{array}$ & $0 \%$ & $23 \%$ & $77 \%$ \\
\hline
\end{tabular}

Note: $n=26$.

The themes, sub-themes and illustrative quotes are reported in Table 3. Although focus-group discussions centred on perception of the six-week rehabilitation programme, participants shared their experience of caring for children with special needs as well as their views of rehabilitative services.

\section{Discussion}

Rehabilitation for children with $\mathrm{CP}$ is crucial to maximise functional ability and improve quality of life for those affected. Often it is the caregivers of the children who are critical to the success of any type of rehabilitation intervention. They adopt the dominant role of executing the necessary intervention and are responsible for the continuity of such programmes, as in the intervention programme used in this study. ${ }^{6}$ Assessing caregivers' satisfaction with any rehabilitation intervention serves as an imperative for the sustainability of such practice. Patient satisfaction studies provide knowledge about means to improve practice ${ }^{4,6,13}$ and also provide relevant information on the marketability of health services and quality of care. ${ }^{14}$ Studies highlight the importance of standardising the tool to assess the level of satisfaction across the different rehabilitation programmes but still no generic instrument is available..$^{15}$ This study used an adapted too ${ }^{13}$ and, although the output of the level of satisfaction questionnaire was overall positive and valuable as it directly impacts treatment outcomes, ${ }^{3}$ the exploratory discussions highlighted significant areas for assisting the rehabilitation of children living with $\mathrm{CP}$ by advocating the view of the caregivers.

The primary caregivers were female and included mothers and a few grandmothers. Similarly, in other studies centred on caregivers of children with $\mathrm{CP}$, the mothers and sometimes grandmother or aunt predominantly adopted the role of primary carer. ${ }^{2,8,16}$ Fathers became the source of income, relegating the primary caring to the female. ${ }^{8}$ In this South African setting, however, a large majority were single women. The role of a single mother caring for a child with special needs adds a different paradigm and will need further investigation.

The myths and beliefs held by caregivers regarding cerebral palsy spanned the belief that the condition is due to witchcraft or a curse on the family, the stress and strain undergone by the mother as well as her behaviour and the chronic medication that the mother administered. This perception inadvertently leads to stigmatisation of the already burdened carer, adding psychosocial stressors. Caregivers of children with $\mathrm{CP}$ in this setting further believed that their lack of understanding, psychosocial barriers and physical stressors challenged them as carers. Other studies reflect that primary carers often experience psychological and physical stressors. ${ }^{8,16}$ Ones et al. ${ }^{8}$ believed that carers of children with CP withdraw from social participation due to their responsibilities and this impacts on their quality of life. Raina et al. ${ }^{2}$ concurred that caring for children with CP does affect psychosocial well-being and Pfeifer et al. ${ }^{16}$ felt that carers are not merely affected physically and socially but financially as well. The majority of caregivers in this study were unemployed and the belief is that the duty to the child is limiting them from obtaining employment.

Augmenting the psychosocial challenges experienced by caregivers were the lack of community support, lack of information, financial constraints and transport barriers that hindered optimal rehabilitative care. In an analogous resourcelimited African setting a study revealed that caregivers of children with CP need added financial and emotional support. ${ }^{3}$ Researchers in the study adopted a decentralised community approach by basing the study at the clinics; this negated the environmental limitations, improved social support and improved the outcomes of a rehabilitation intervention programme compared with an institutional based health setting making specific appointments for rehabilitation sessions. ${ }^{3}$ This is supported by another South African study advocating that community-based interventions provide psychosocial support, support relationships and improve social functioning and selfesteem. ${ }^{17}$ In another study in Turkey looking at the quality of life of mothers of children with $\mathrm{CP}$ as primary caregivers, researchers corroborate that lack of resources and transport limitations pose a challenge to caregivers' primary role. Barnes and Good ${ }^{18}$ highlighted the advantages of community-based rehabilitation as improving these limitations through family involvement, decreasing costs and providing home and community support.

The perceptions of caregivers of children with cerebral palsy toward rehabilitation and health care in this paper included untimely referral, scarcity of information from healthcare staff, poor consultation with the healthcare team and lack of communication. Studies by Dambi and Jelsma ${ }^{3}$ and Ones et al. ${ }^{8}$ concur that a lack of information hinders caring for children with $\mathrm{CP}$ optimally. Likewise, in a Norwegian study with carers of children with $\mathrm{CP}$, similar challenges of inadequate information 
Table 3: Thematic representation of caregivers' understanding of CP and their challenges to rehabilitation

\begin{tabular}{|c|c|}
\hline Sub-theme & Quotes \\
\hline \multicolumn{2}{|l|}{ Myths and beliefs about cerebral palsy } \\
\hline & 'Our ancestors were angry and caused the child to be sick' (Caregiver 3) \\
\hline Witchcraft or curse & $\begin{array}{l}\text { 'Her father took her to his family before they performed necessary rituals for her. That made the ancestors angry' } \\
\text { (Caregiver 8) }\end{array}$ \\
\hline Mother's stress caused cerebral palsy & 'My daughter was abused by the child's father when she was pregnant that is why he is like this' (Caregiver 7) \\
\hline Mother's medication as a cause of cerebral palsy & 'It is the tablets that I take when I was pregnant that caused the child to be disabled' (Caregiver 10) \\
\hline Behaviour as a cause & $\begin{array}{l}\text { 'An arrogant or rude mother can cause the child to be sick' (Caregiver 1) } \\
\text { 'If we being shouted at a lot when mom was pregnant' (Caregiver 2) }\end{array}$ \\
\hline
\end{tabular}

Perceptions of caregivers of children with cerebral palsy toward rehabilitation and health care

'I get help but they ordered wrong shoes for him [physiotherapy referral to orthotist] and it took a long time to do

Untimely referral so' (Caregiver 4)

'I tell them there at physio to give him a chair, they take long to get it from the other therapist [Referring to OT]' (Caregiver 6)

'To me they said that there was blood in her brain. But did not explain how it got there or what challenges I will face with her, I only heard at physio that she had cerebral palsy (Caregiver 11)

Scarcity of information from healthcare staff

'For me they said she had cerebral palsy, marked with cerebral atrophy and small head. I can see the small head but do not understand what the other stuff means' (Caregiver 8)

Poor consultation with healthcare team

'Depends on person attending you. Some are nice and help, others don't explain to us. They just look at the child and you don't know what they are doing. They would not even explain like you did here [referring to 6-week programme] and just give you your next appointment' (Caregiver 20)

'No one explains to us the results of these CT scans they do and what it means and what will happen to his body' (Caregiver 7)

Lack of communication from rehabilitation team

'They just tell us that the child has delayed milestone. But what does it mean, At least here you tell us more [referring to 6-week programme], later the child presents this way' (Caregiver 19)

'Attending physiotherapy clinic helps. My child was tight now is better. She can now walk for short distances, exercises helped a lot' (Caregiver 14)

Rehabilitation benefits children

'Exercises and advice was to sit him for long to strengthen muscles of his body and head. That helped me' (Caregiver 7)

'What help me and my child was physiotherapy. My child could not turn and laugh but now can' (Caregiver 10)

Intrinsic inhibitors of caregivers

Lack of understanding

'My child could not speak. After I started attend speech now I can understand when she talks, it's still not very clear but I can hear her now' (Caregiver 8)

'I just don't know what to do when he does not want to eat and when he chokes on drinking and during feeding. No one tells us what to do' (Caregiver 10)

'I don't have friends because they laughed at me and my child because she was disabled and the father left us as soon as the child was sick. My mom is my friend now' (Caregiver 8)

Psychosocial barriers

'I just worry when he is sick with flu or when get a fits because I know after that he will get sicker and they might think I don't take care of him. Sometimes I don't even attend therapy when he is not well' (Caregiver 23)

'I stress a lot when I think about him and his future. I just don't know what will happen to him when I die because we are both sick and no one supports us' (Caregiver 10)

Physical stressors

'For me lack of sleep stresses me. I sometimes have to be up all night and he cries and do not want to go to sleep. The next morning I'll still have to go to work' (Caregiver 22)

Extrinsic barriers to caring for children with cerebral palsy

Lack of community support

Stigma

Lack of information

Financial constraints
'People laugh at you when you walking with your disabled child. People laugh all the time. It's very sad' (Caregiver 19)

'Some people in the community would look at you and think that you deserved having a child like this more especially when you are young like us. They say we did not listen to our parents and we are cursed' (Caregiver 10)

'People still don't know that our kids with disability are a gift like other kids. Some mothers I know don't walk with them but they get paid for disability grant. I walk with my child and I'm not ashamed' (Caregiver 18)

'Finances are always a challenge for me. I sometimes do not have money to take him to hospital for his physiotherapy appointment because I need money for three people to be able to ride the taxi' (Caregiver 14

'My family does not support me. Being alone with no one to support is hard [no support from the father and also financially]' (Caregiver 10) 
Table 3: (Continued)

\begin{tabular}{|c|c|}
\hline Sub-theme & Quotes \\
\hline Transport barriers & $\begin{array}{l}\text { 'Some taxis would stop for you, but when they see that you have a disabled child on a buggy they would just leave } \\
\text { you and rush say they are rushing. I hire a private car every time I come for therapy' (Caregiver 17) }\end{array}$ \\
\hline \multicolumn{2}{|c|}{ Personal enablers to coping with caring for child with cerebral palsy } \\
\hline Spiritual and religious support & 'Prayer helped me. I feel less sad as I pray' (Caregiver 7) \\
\hline \multicolumn{2}{|l|}{ Recommendations by caregivers } \\
\hline Community-awareness strategies & $\begin{array}{l}\text { 'I think I would tell the community to take their kids to the clinics if they see that their growth is slower or they are } \\
\text { later than the other kids same age to advise about caring for their children' (Caregiver 8) }\end{array}$ \\
\hline Support groups & $\begin{array}{l}\text { 'Meet with other mothers to encourage them to take step to help their kids. For example, I attend clinics and I con- } \\
\text { tinue with their therapy programmes because at a long run they help. I'll tell them about my child' (Caregiver 14) }\end{array}$ \\
\hline
\end{tabular}

concerning services were discussed. ${ }^{6}$ Myrhaug et al., ${ }^{6}$ in their work on family-centred services, believed that parental involvement is essential to rehabilitation, as well as adequate information and the sharing of in-service delivery. The lack of information as perceived in this study could be due to the lack of staff and high patient volume. The rehabilitation staff shortage is recognised in South Africa as a barrier to optimal rehabilitation., ${ }^{710}$ Dambi and Jelsma's study also factored high patient volumes versus staff complement as a possible barrier to sharing necessary information. ${ }^{3}$ The South African Health care system is premised on 11 Batho Pele Principles, which advocate adequate information being shared when caring for patients, ${ }^{19}$ including children with $\mathrm{CP}$ and caregivers alike, which is contradicted in the delivery of care as perceived by caregivers in the present study. Hence, further research is critical to explore how to translate these principles into practice in a South African context.

Personal enablers in coping with caring for a child with cerebral palsy in this study were spiritual and religious support. Additionally, community-awareness strategies and support groups were recommended by caregivers to improve the challenges experienced with rehabilitation. Studies with caregivers of children with CP showed that caregivers seek support from others who are in similar situations and often meet in therapeutic environments. ${ }^{20,21}$ These support groups for caregivers have been affirmed as vital and are believed to assist with emotional and informational support. ${ }^{16}$ Pfeifer et al. argued, though, that social support provided by extended family, friends and neighbours was a secondary mechanism to the immediate family nucleus. ${ }^{16}$ Moreover, it is evident that focusing on the family improves rehabilitation outcomes and family support for a child living with a disability. ${ }^{6}$ However, researchers believe that added social support improves psychosocial well-being. ${ }^{22}$. Involving the community is also believed to enhance caregivers' satisfaction and rehabilitation outcomes ${ }^{11}$ in providing holistic care to children with special needs.

\section{Conclusion}

A holistic approach to individualised assessment, intervention planning and rehabilitation of children with $\mathrm{CP}$ should be implemented for quality patient-centred care. The utilisation of a nonconventional contextualised rehabilitation programme as in this study may prove beneficial in resource-limited settings such as South Africa. The aim of this community-based programme was to provide a support structure and education as well as to improve access for the caregivers. Consequently findings revealed high levels of satisfaction with its implementation. However, accessing such services is still plagued by poverty. Financial instability, transport barriers and other environmental barriers inhibit carers accessing such care even though it was placed within the community. This study did, however, aim to equip the caregivers with knowledge and skills that could be translated into a home-based rehabilitation programme. This task-shifting approach attempts to bridge the gap and enable continuity of the rehabilitation programme.

\section{Limitations}

The long-term effects of capacitating caregivers need to be evaluated in order to understand whether this approach is appropriate for a South African context. The study is focused on one of the nine provinces in SA and thus has its own restrictions in generalisability of findings.

\section{References}

1. Centers for disease control and prevention. Data \& statistics for cerebral palsy, prevalence and characteristics. 2016; [cited 2016 Jun]. http://www.cdc.gov/ncbddd/cp/data.html

2. Raina $P, O^{\prime}$ Donnell $M$, Rosenbaum $P$, et al. The health and wellbeing of caregivers of children with cerebral palsy. Pediatrics 2005;115(6):e626-36. http://dx.doi.org/10.1542/peds.2004-1689

3. Dambi JM, Jelsma J. The impact of hospital-based and community based models of cerebral palsy rehabilitation: a quasi-experimental study. BMC paediatrics 2014;14(1):1-10.

4. GannottiME, Law M, Bailes AF, etal.Comparative effectiveness research and children with cerebral palsy. Pediatr Phys Ther. 2016;28(1):58-69. http://dx.doi.org/10.1097/PEP.0000000000000203

5. Rosenbaum P, Paneth $\mathrm{N}$, Leviton $\mathrm{A}$, et al. A report: the definition and classification of cerebral palsy April 2006. Dev Med Child Neurol Suppl. 2007;109(suppl 109):8-14.

6. Myrhaug HT, Jahnsen $\mathrm{R}, \varnothing$ stensjø S. Family-centred practices in the provision of interventions and services in primary health care: a survey of parents of preschool children with cerebral palsy. J Child Health Care. 2014. doi: 10.1177/1367493514551312.

7. Levin K. 'I am what I am because of who we all are': international perspectives on rehabilitation: South Africa. Pediatr Rehabil. 2006;9(3):285-92. http://dx.doi.org/10.1080/13638490500293358

8. Ones K, Yilmaz E, Cetinkaya B, et al. Assessment of the quality of life of mothers of children with cerebral palsy (primary caregivers). Neurorehabilitation and Neural Repair 2005;19(3):232-7. http://dx.doi.org/10.1177/1545968305278857

9. World Health Organisation. Being an effective team player. 2005 [cited 2016 Jun]. Available from: http://www.who.int/patientsafety/ education/curriculum/who_mc_topic-4.pdf.

10. Chetty V, Hanass-Hancock J, Myezwa H. Expert consensus on the rehabilitation framework guiding a model of care for people living with hiv in a south african setting. J Assoc Nurses AIDS Care. 2016;27(1):77-88. http://dx.doi.org/10.1016/j.jana.2015.10.003

11. Gannotti ME, Christy JB, Heathcock J, et al. A path model for evaluating dosing parameters for children with cerebral palsy. Phys Ther. 2014;94(3):411-21. http://dx.doi.org/10.2522/ptj.20130022

12. Hussein $A$. The use of triangulation in social sciences research: Can qualitative and quantitative methods be combined? J Comp Social Work. 2015;4(1):1-12.

13. Ireys HT, Perry JJ. Development and evaluation of a satisfaction scale for parents of children with special health care needs. Pediatr 1999;104(Supplement 6):1182-91. 
14. Keith RA. Patient satisfaction and rehabilitation services. Arch med rehabil. 1998;79:1122-8. http://dx.doi.org/10.1016/S00039993(98)90182-4

15. Horne R, Hankins M, Jenkins R. The satisfaction with information about medicines scale (SIMS): a new measurement tool for audit and research. Quality in health care 2001;10(3):135-40. http://dx.doi.org/10.1136/qhc.0100135

16. Pfeifer LI, Silva DBR, Lopes PB, et al. Pinto MPP. Social support provided to caregivers of children with cerebral palsy. Child Care Health Dev. 2014;40(3):363-9.

17. Killian B. Risk and resilience. A generation at risk. 2004; 33-63.

18. Barnes, MP, Good, DC editors. Neurological rehabilitation: handbook of clinical neurology (Vol. 110). Oxford: Newnes; 2013.

19. Neille J, Penn C. Beyond physical access: a qualitative analysis into the barriers to policy implementation and service provision experienced by persons with disabilities living in a rural context. Rural and remote health. 2015;15(3332):1-15.

20. MilbrathVM,CecagnoD,SoaresDC,etal.Beingawoman, mothertoachild with cerebral palsy. Acta Paulista de Enfermagem. 2008;21(3):427-31. http://dx.doi.org/10.1590/S0103-21002008000300007

21. Davis E, Shelly A, Waters E, et al. The impact of caring for a child with cerebral palsy: quality of life for mothers and fathers. Child Care Health Dev. 2010;36(1):63-73.

22. Carona C, Crespo C, Canavarro MC. Similarities amid the difference: caregiving burden and adaptation outcomes in dyads of parents and their children with and without cerebral palsy. Res Dev Disabil. 2013;34(3):882-93. http://dx.doi.org/10.1016/j.ridd.2012.12.004

Received: 22-07-2016 Accepted: 24-10-2016 